\title{
Lung Transplantation and Precision Medicine
}

\author{
Hanne Beeckmans, Berta Saez, Anke Van Herck, \\ Annelore Sacreas, Janne Kaes, Tobias Heigl, \\ Arno Vanstapel, Sofie Ordies, Anna E. Frick, \\ Stijn E. Verleden, Geert M. Verleden, Robin Vos, \\ and Bart M. Vanaudenaerde
}

\begin{tabular}{ll}
\hline Abbreviations \\
AATD & $\begin{array}{l}\text { Alpha-1 antitrypsin deficiency } \\
\text { Acute fibrinous and organizing } \\
\text { pneumonia } \\
\text { Aforte lung allograft dysfunction }\end{array}$ \\
ALAD & $\begin{array}{l}\text { Antibody-mediated rejection } \\
\text { AMR }\end{array}$ \\
ARAD & $\begin{array}{l}\text { Azithromycin responsive allograft } \\
\text { dysfunction }\end{array}$ \\
ARDS & $\begin{array}{l}\text { Acute respiratory distress syndrome } \\
\text { Bronchoalveolar lavage }\end{array}$ \\
BAL & $\begin{array}{l}\text { Bronchiolitis obliterans syndrome } \\
\text { BOS }\end{array}$
\end{tabular}

H. Beeckmans - B. Saez · A. Van Herck · A. Sacreas ·

J. Kaes · T. Heigl - A. Vanstapel - S. Ordies · A. E. Frick · S. E. Verleden · G. M. Verleden · R. Vos KU Leuven and University Hospitals Leuven, Department of Chronic Diseases, Metabolism and Ageing (CHROMETA), Division of Respiratory Diseases, Lung Transplant Unit, Leuven, Belgium e-mail: bsaez@vhebron.net; anke.vanherck@kuleuven.be; annelore.sacreas@kuleuven.be; janne.kaes@kuleuven.be; tobias.heigl@kuleuven.be; arno.vanstapel@kuleuven.be; sofie.ordies@kuleuven.be; annaelisabeth.frick@uzleuven.be; stijn.verleden@kuleuven.be; geert.verleden@kuleuven.be; robin.vos@uzleuven.be

B. M. Vanaudenaerde $(\bowtie)$

Department of Chronic Diseases, Metabolism and Ageing (CHROMETA), Lab of Respiratory Diseases, Lung Transplantation Unit, KU Leuven and UZ Leuven, Leuven, Belgium e-mail: bart.vanaudenaerde@kuleuven.be; bart. vanaudenaerde@med.kuleuven.be
CF

CLAD

COPD

CT

DAD

DSA

ECD

EVLP

$\mathrm{FEV}_{1}$

$\mathrm{FiO}_{2}$

FVC

HLA

HRCT

ICU

IPF

ISHLT International Society of Heart and Lung Transplantation

LB Lymphocytic bronchiolitis

MMF Mycophenolate mofetil

NRAD Neutrophilic reversible allograft dysfunction

OB Obliterative bronchiolitis

PAH Pulmonary arterial hypertension

$\mathrm{PaO}_{2} \quad$ Arterial partial pressure of oxygen

PEEP Positive end-expiratory pressure

PGD Primary graft dysfunction

PPFE Pleuroparenchymal fibroelastosis

QoL Quality of life

RAS Restrictive allograft dysfunction 
r-CLAD Restrictive chronic lung allograft dysfunction

SCD Standard-criteria donor

\section{Introduction}

The history of lung transplantation starts in the 1940s: researchers tried to perform lung transplantation, initially in laboratory animals followed by human to human. Many of these early attempts were unsuccessful, and even after successful lung transplantation, most lungs were ultimately rejected despite the use of various immunosuppressants available at that time. The first human single lung transplantation was performed in 1963 by James Hardy in Mississippi, using the left lung of a circulatory death donor. The patient survived for 18 days before dying of renal failure. Over the next decade, many more lung transplantations were performed, with limited success: few patients survived over 2 weeks. At that time, the leading causes of death were peri-operative problems. Subsequent improvements in surgical techniques and especially the introduction of immunosuppressive drugs such as cyclosporin and tacrolimus resulted in rapid progress in the 1980s, with the first successful heart-lung transplantation in 1981 in Stanford by Bruce Reitz and the first single lung transplantation in Toronto in 1983 by Joel Cooper [1]. The second successful lung transplantation from a circulatory death donor was reported by Steen [2]. These advances led to higher success rates and transplant centers all over the world started developing their programs. Today over 100 transplant centers in Europe and North America are active, although the majority of lung transplantations is still performed in a small number of highly specialized centers (see Fig. 22.1). As short-term survival improved substantially, more patients developed long-term complications [3]. These long-term complications compromised the initially increased quality of life (QoL) due to restored normal pulmonary function [4].

Nowadays, lung transplantation is an accepted therapeutic option for many end-stage lung diseases like chronic obstructive pulmonary disease (COPD), Alpha-1 antitrypsin deficiency (AATD), cystic fibrosis (CF), idiopathic pulmonary fibrosis (IPF), pulmonary fibrosis due to other causes (i.e. hypersensitivity pneumonitis, sarcoidosis, scleroderma, rheumatoid arthritis) and pulmonary arterial hypertension (PAH) [5]. There are four main types of lung transplantation; the choice of transplantation type depends on the indication, age, and patient characteris-
Fig. 22.1 Average center volume for lung transplantation (not including heart-lung transplants)

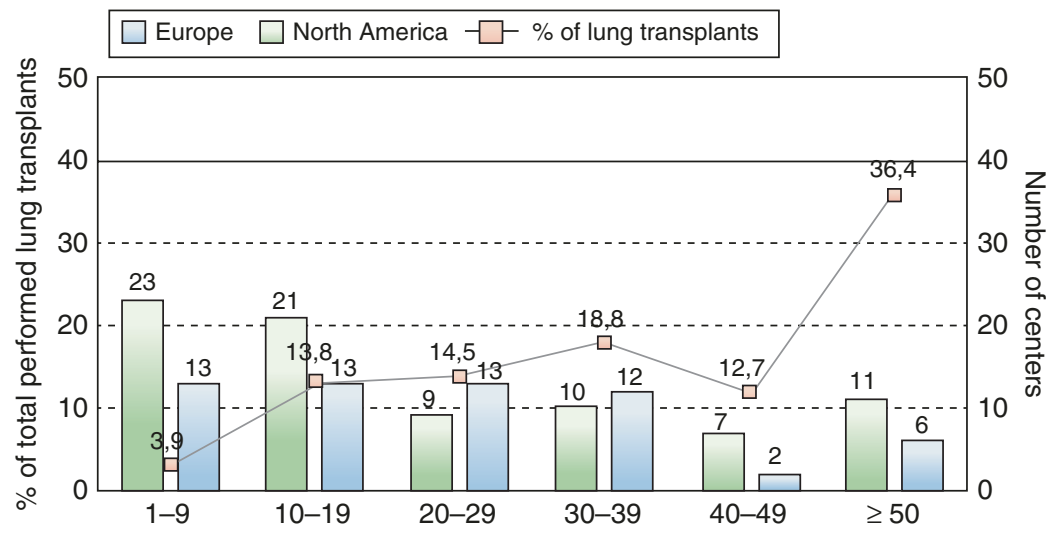

Average number of lung transplants per year in Europe and North America. Based on data from the International Society of Heart and Lung transplantation from January 2009 till June 2017 
Table 22.1 Indications and contraindications for lung transplantation [13, 14]

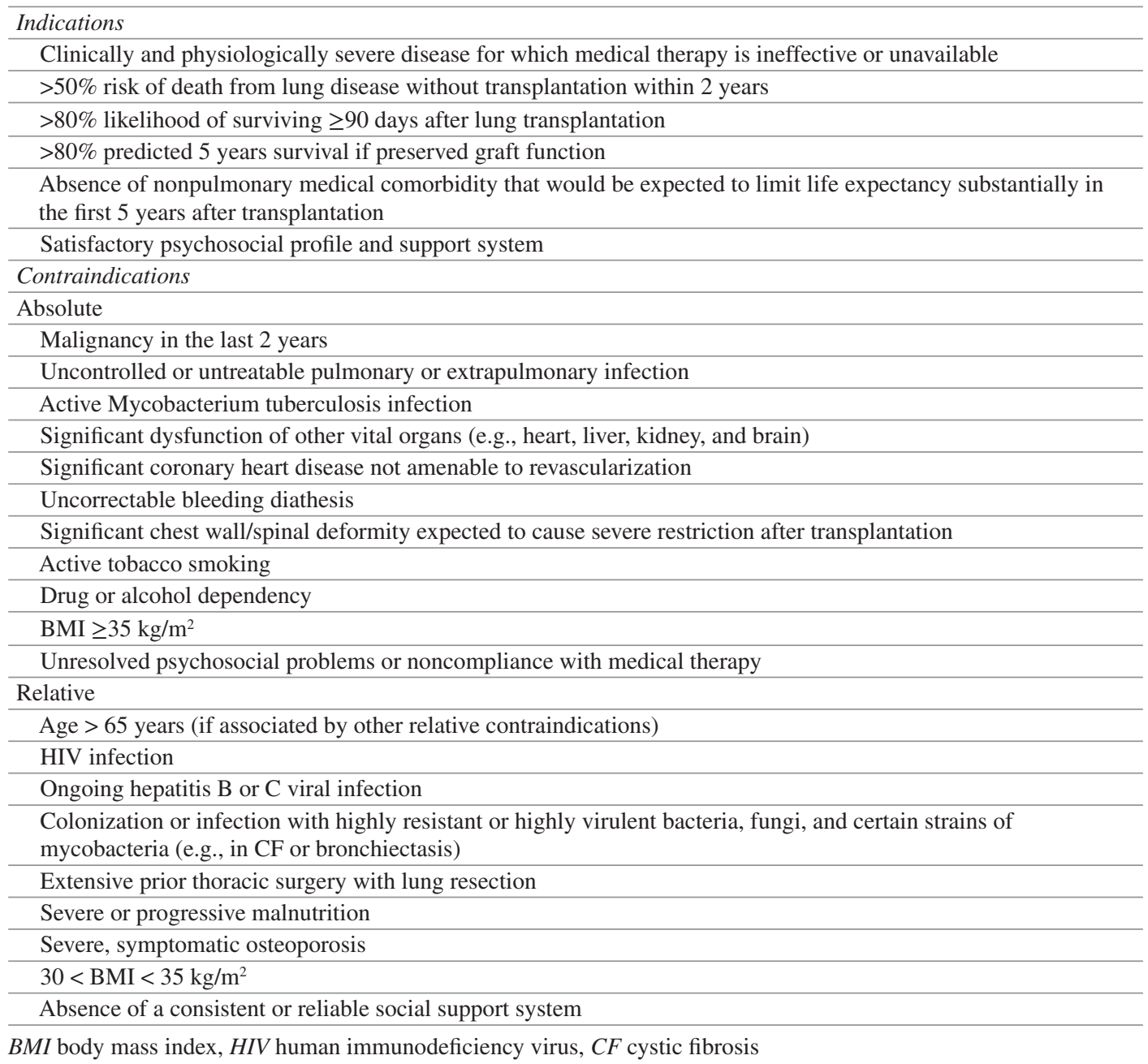

tics. First, heart-lung transplantation is performed with the assistance of cardiopulmonary bypass, and mainly for pulmonary arterial hypertension. The second type is unilateral lung transplantation, which is increasingly rarer, where the least functional lung is replaced, mainly used for older pulmonary fibrosis or COPD patients. Third and most practiced, double lung transplantation, where both lungs are sequentially replaced by a donor lung, which can sometimes be performed without the use of a cardiopulmonary bypass. Finally, lobar lung transplantation is even more seldom performed than unilateral lung transplantation. For example, when young patients with $\mathrm{CF}$ undergo living donor lobar transplant from their parents in the event of lacking a suitable donor (living-related donor transplantation), or when there is a considerable size mismatch between a large donor and a small receptor. In 2016, the International Society of Heart and Lung Transplantation (ISHLT) reported 62 heart-lung transplantations, 3.748 bilateral lung transplantations, and 913 single lung transplantations.

Lung transplantation is not possible without donors. Due to the lack of experience, donor's lungs were initially selected very strictly [6]. However, over the last decade, with increased experience, leading transplant centers started to progressively use more donor lungs that do not 
fully meet these criteria, to make up for the shortage of lung donors [7, 8]. Also, the donor lung was initially preserved on ice, inducing cold ischemia, and consequently leading to damage of the donor lung. Some centers reported good results using ex-vivo lung perfusion (EVLP), in which the lung is perfused outside of the body $[9,10]$. Immediately after lung transplantation, numerous complications can occur, varying from primary graft dysfunction (PGD), infection to acute rejection, among others. The major long-term complication still consists of gradually increasing shortness of breath, due to progressive deterioration of pulmonary function, known as chronic lung allograft dysfunction (CLAD). CLAD is regarded as the main limitation to long-term survival after lung transplantation, namely $57 \%$ 5-year survival, which is still limited compared to other solid organ transplantations (i.e., after kidney transplantation a 10 -year all-cause graft failure of $51.6 \%$ is reported) $[11,12]$. The best-studied phenotypes of CLAD are bronchiolitis obliterans syndrome (BOS) and restrictive allograft dysfunction (RAS).

This chapter will discuss the many specialized procedures involved in lung transplantation, starting with the selection of donors and recipients, care for the donor lung, acute complications, and their prevention; and finally the most pressing issue in lung transplantation today: CLAD.

Table 22.2 Standard-criteria lung donor [6]

\begin{tabular}{l}
\hline Age $<55$ years \\
\hline ABO compatibility \\
\hline Clear serial chest X-ray \\
\hline Normal gas exchange $\left(\mathrm{PaO}_{2}>300 \mathrm{~mm} \mathrm{Hg}\right.$ on $\mathrm{FiO}_{2}$ \\
1.0, PEEP $\left.5 \mathrm{~cm} \mathrm{H}_{2} \mathrm{O}\right)$ \\
\hline$\leq 20$-pack-year smoking history \\
\hline Absence of chest trauma \\
\hline No previous surgery on side(s) of harvest \\
\hline No evidence of aspiration or sepsis \\
\hline Absence of purulent secretions at bronchoscopy \\
\hline Absence of organisms on sputum gram stain \\
\hline Appropriate size match with prospective recipient \\
\hline $\mathrm{PaO}_{2}$ arterial partial pressure of oxygen, $\mathrm{FiO}$ fractional \\
inspired oxygen, $\mathrm{PEEP}$ positive end-expiratory pressure
\end{tabular}

\section{Surgical Issues}

Lung transplantation is considered for patients with end-stage lung diseases who, despite maximal medical or surgical therapy, experience a decline in clinical status. This usually means patients who have a limited life expectancy over the next 2 years and are symptomatic during activities of daily living. Indications and contraindications for lung transplantation have been developed by the ISHLT and are listed in Table $22.1[13,14]$.

Not all organ donors are suitable to be lung donors. Strict criteria of the "standard-criteria lung donor" (SCD) have previously been defined; donors meeting these criteria are considered "ideal" (Table 22.2) [6]. Only 15-25\% of all multi-organ donors are suitable for lung transplantation, due to injury from cardio-pulmonary resuscitation, lung contusion, airway aspiration, and pulmonary infection at the time of brain insult, as well as underlying lung disease [15]. This scarcity of suitable donor organs leads to persistent mortality of patients on the waiting list; and thus these criteria have been liberalized to "extended-criteria lung donors" (ECD) in order to increase the number of transplantable donor organs $[7,8]$. ECD are lung donors not matching the strict criteria of an SCD, for example, because of pre-existing conditions, a smoking history of more than 20 pack-years or hepatitis, among others. There is no consensus about ECD, and multiple centers report different criteria [16-20]. This increase of transplantable lungs is associated with a negative impact on early outcome: prevalence of severe PGD, length of stay in intensive care unit (ICU) and duration of mechanical ventilation $[16,18]$. There is still debate about whether the use of ECD lungs compromises long-term clinical outcomes [17-20]. Figure 22.2 shows the increased use of ECD lungs in lung transplantation [16].

Up till now, donor's lungs were mainly stored on ice; EVLP is an alternative to cold static lung preservation and a new form of isolated lung perfusion in normothermic conditions. It is achieved using a pump-driven perfusion machine that recirculates a preservation solution through the 


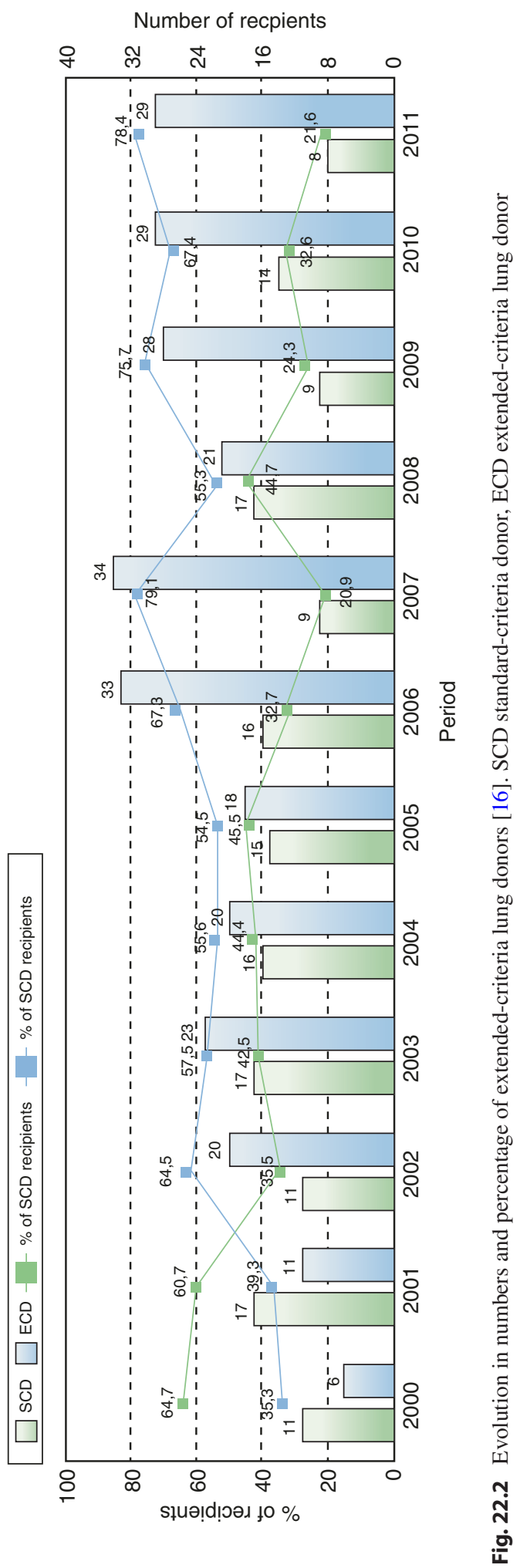


vasculature of the lung in addition to protective mechanical ventilation. The main potential benefit is, in the first place, longer storage time (up to 18 hours, compared to cold storage preservation, which can only preserve the lung up to 6 hours) and the resultant optimization of logistics for lung transplantation $[9,10]$. Secondly, the possibility of reconditioning the lung and, therefore, the possibility of transplantation of lungs that otherwise would not be used [21-25]. However, in several centers, many of the lungs initially not considered transplantable are already transplanted as an ECD lung without the use of EVLP, with comparable results in large experienced centers $[16,26]$. Thus, clinical trials still have to demonstrate if the potential advantages weigh against the costs of the EVLP.

Another new development in lung transplantation is the use of extracorporeal lung support, which can be utilized to bridge deteriorating patients to lung transplantation. This is not a commonly used technique, although there are promising results, with bridging up to 140 days, which could reduce mortality on the waiting list [27-30].

\section{Acute Lung Allograft Dysfunction}

Every lung transplantation patient receives lifelong treatment with immunosuppressive drugs in order to avoid rejection of the graft by the immune system. Standard maintenance therapy consists of triple-drug therapy, including a calcineurin inhibitor (cyclosporin or tacrolimus), an antiproliferative agent (azathioprine or mycophenolate mofetil (MMF)) and a corticosteroid (e.g., prednisolone), although protocols may vary from center to center [31].

In the years after transplantation, patients may develop an acute deterioration of pulmonary function status, with a rapid increase in shortness of breath. This is known as acute lung allograft dysfunction (ALAD). Many conditions causing ALAD are known and can be treated, after which the $\mathrm{FEV}_{1}$ and forced vital capacity (FVC) should usually restore to baseline values. If, however, the pulmonary function decline is not restored to
$>90 \%$ of baseline and maintains for at least 3 weeks, CLAD may be suspected [32].

First, primary graft dysfunction (PGD) is a common complication that occurs immediately after lung transplantation, resulting in acute failure of the graft. In the past, it was also referred to as ischemia-reperfusion injury, early graft dysfunction, primary graft failure or re-implantation edema. PGD occurs within the first 72 hours after lung transplantation and is characterized by severe hypoxemia, lung edema with diffuse alveolar damage and radiographic evidence of diffuse pulmonary infiltration without other identifiable cause (Fig. 22.3). The radiographic and histological findings resemble acute respiratory distress syndrome (ARDS) [33-37]. Several harmful events may contribute to the development of PGD, such as prolonged mechanical ventilation, prolonged warm ischemia, cold ischemia during storage in cold preservation solution, reperfusion, and peri-operative insults. Several risk factors exist and are summarized up in Table 22.3 [38-40]. This complication leads to prolonged length of mechanical ventilation, prolonged ICU stays, prolonged hospital stay and even increased short-term mortality, but may also have an impact on long-term survival, as it might impact the later development of BOS, a phenotype of CLAD [4145]. This long-term impact may, however, be modified by accurate treatment. Only supportive

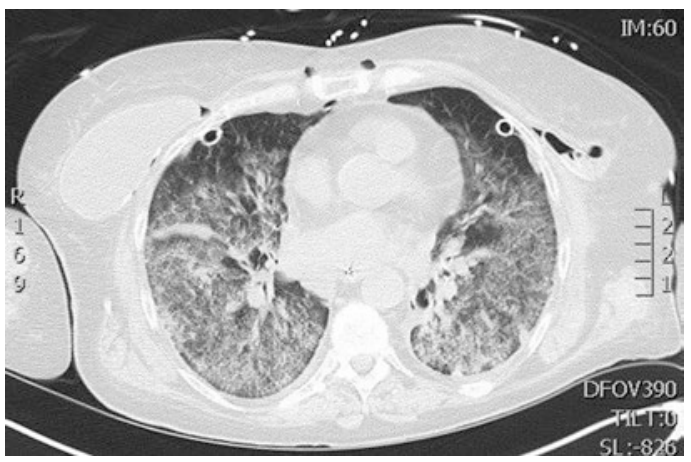

Fig. 22.3 CT at 72 hours posttransplantation of a patient diagnosed with PGD. PGD scores were 1, 3, and 2 at 24, 48 , and 72 hours of posttransplantation, respectively, according to the ISHLT grading system of PGD [37]. CT computed tomography, PGD primary graft dysfunction, ISHLT International Society for Heart and Lung Transplantation 
Table 22.3 Risk factors for development of primary graft dysfunction [38-40]

\begin{tabular}{l}
\hline Donor-related factors \\
\hline Donor smoking (especially $>20$ pack years) \\
\hline Operative-related factors \\
\hline Single-lung transplant \\
\hline Prolonged cold ischemic time \\
\hline High fractional inspired oxygen upon reperfusion \\
\hline Poly-transfusion \\
\hline Intracellular type preservation solutions \\
\hline Use of cardiopulmonary bypass \\
\hline Recipient-related factors \\
\hline BMI $\geq 25$ \\
\hline Sarcoidosis \\
\hline IPF \\
\hline Primary PAH \\
\hline Increased pulmonary arterial pressures
\end{tabular}

$B M I$ body mass index, IPF idiopathic pulmonary fibrosis, $P A H$ pulmonary arterial hypertension

Table 22.4 Category of infections in function of time [50]

\begin{tabular}{l}
\hline $\begin{array}{l}\text { First post-operative month } \\
\text { Infections with microbes present in the donor or } \\
\text { recipient }\end{array}$ \\
\hline Nosocomial infections \\
\hline $\begin{array}{l}\text { Infections related to technical problems (e.g., } \\
\text { catheter infections) }\end{array}$ \\
\hline 1-6 months after transplantation \\
\hline Opportunistic infections \\
\hline Reactivation of latent infections \\
\hline 6 months or more after transplantation \\
\hline Infections due to community-acquired pathogens
\end{tabular}

treatment is available for PGD, including lungprotective ventilation, restrictive fluid balance, inhaled nitric oxide (iNO), and finally extracorporeal membrane oxygenation (ECMO) [38, 4648]. No preventive treatment options have proven to be effective, and retransplantation can be considered, but predicted survival in this setting is poor, and therefore retransplantation for severe PGD is not recommended [49].

Moreover, as a result of the mandatory lifelong immunosuppression and its resultant immune system impairment, lung transplant patients are more vulnerable to infectious agents, both bacterial, viral and fungal [50]. Infection should therefore always be excluded before a diagnosis of acute allograft rejection is made [51]. There are four main clinical scenarios resulting in an infection in a lung transplant patient. First of all, recipients can host infections from a wide range of microorganisms prior to transplantation (especially patients with $\mathrm{CF}$ ). Second, colonization with nosocomial organisms occurs frequently during hospitalization. Third, lung grafts could transfer infections from donors to recipients. Finally, transplanted patients are, as previously mentioned, more prone to severe community-acquired or nosocomial infections with relatively innocuous infectious [52]. Time affects which type of infection a lung transplant patient can develop (Table 22.4) [50]. However, infections are more difficult to diagnose in lung transplant patients as classic symptoms such as fever, loss of appetite, fatigue, chills, night sweats and pain may be unremarkable or absent, whereas white blood cell count is commonly altered due to immunosuppressive therapy; also, loss of lung function may be observed in lung infection but is also a common trait in acute and chronic rejection. The main technical investigations that should be undertaken to diagnose an infection and differentiate between infection and rejection are a bronchoalveolar lavage (BAL) with culture, transbronchial biopsies and chest computed tomography (CT).

Another frequent complication is acute lung allograft rejection, especially during the first year after lung transplantation, which does not cause mortality per se is frequently treatable with a short pulse of IV steroids. However, mortality should not be neglected as $3.6 \%$ of deaths among adult lung transplant recipients within the first 30 days, respectively, and 1.8\% up to 1-year posttransplant are attributable to acute rejection. Twenty-nine percent of adult patients experience at least one episode of treated acute rejection between discharge from the hospital and 1-year follow-up after transplant $[51,53]$. This complication should not be underestimated as patients who suffer one or more episodes of acute rejection already have a higher risk for later CLAD [51]. Symptoms are nonspecific and may include cough, dyspnea, fever, leukocytosis, and an increased alveolar- 

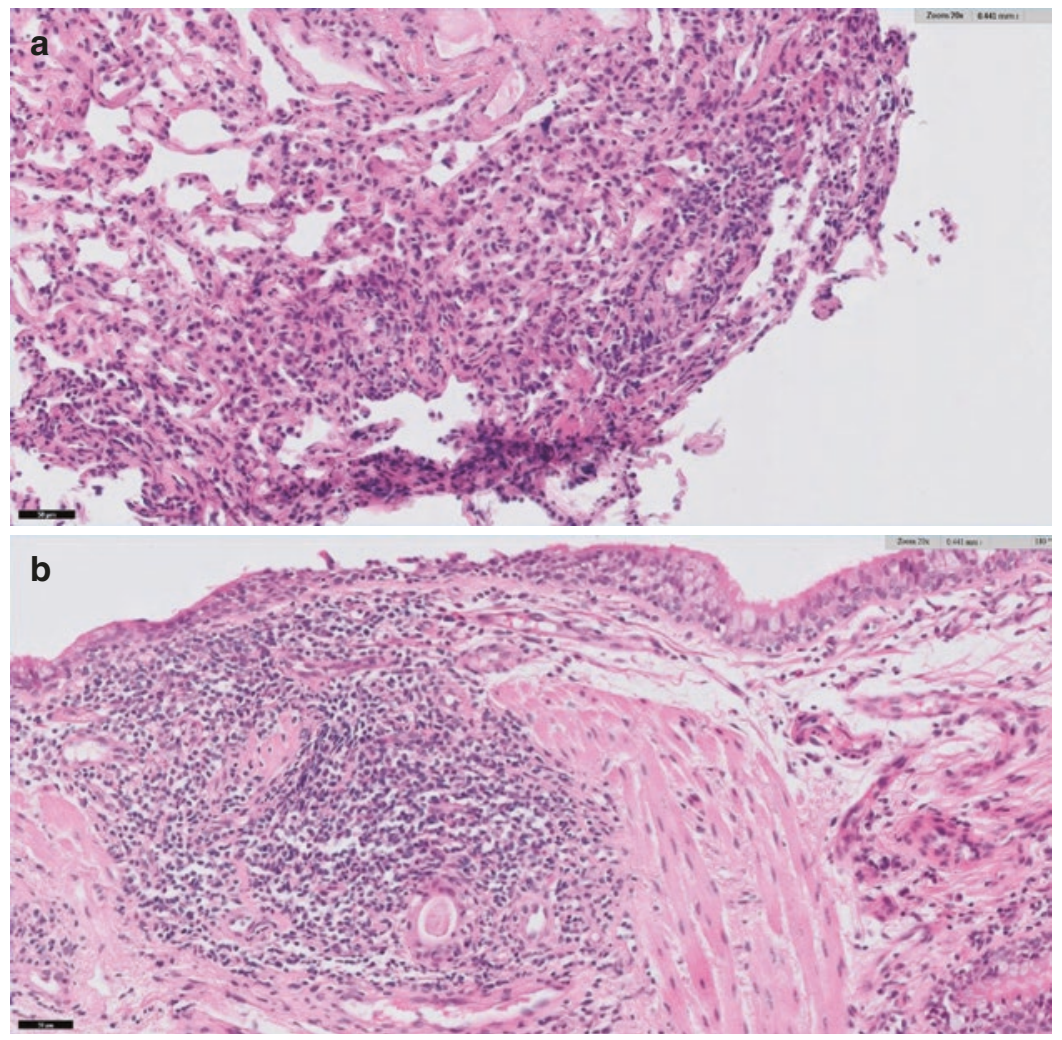

Fig. 22.4 Histopathological findings in patients with acute lung allograft rejection [55]. (a) Minimal acute cellular rejection (grade A1, ×40). The hallmark feature of acute cellular rejection is the presence of truly circumferential perivascular cellular infiltrates around blood vessels in the alveolar parenchyma, particularly small veins. These perivascular cuffs consist of mononuclear cells, two to three cells in thickness. Eosinophililic infiltration, endothelialitis or expansion of the cellular infiltrate into the alveolar septa is absent in minimal acute rejection. (b)

arterial oxygen gradient. High resolution computed tomography (HRCT) of the chest may show ground-glass opacities and septal thickening, which are nonspecific features [54]. Risk factors for acute rejection are genetic predisposition, human leukocyte antigen (HLA) mismatch and the type of immunosuppressive treatment [54]. Transbronchial biopsies remain the gold standard for diagnosis of acute allograft rejection and to discriminate it from aspiration, infection, drug toxicity, or recurrent disease [51]. There are different types of acute lung allograft rejection, first the classic and most frequent form of acute lung allograft rejection:
High-grade lymphocytic bronchiolitis (grade B2R). The lamina propria contains a prominent infiltrate of activated lymphocytes; admixed with some plasmacytoid cells, neutrophils, and eosinophils. This mononuclear infiltrate extends into the epithelium, with the presence of prominent intra-epithelial lymphocytes. The overlying epithelium further shows signs of epithelial damage, evidenced by necrosis and apoptosis. (Representative pictures from selected cases from the KULeuven Lung Transplant Unit)

acute cellular rejection, which is divided into A-grade rejection and B-grade rejection: lymphocytic bronchiolitis (LB). A-grade rejection is characterized by perivascular rejection and is mediated by $\mathrm{T}$ lymphocytes that recognize foreign HLAs or other antigens. Transbronchial biopsy displays perivascular and interstitial mononuclear cell infiltrates (Fig. 22.4a), whereas BAL presents elevated lymphocyte and neutrophil counts [54]. LB is considered an acute rejection of the small airways mediated by T-lymphocytes, peribronchial mononuclear cell infiltration and sometimes epithelial damage of the airways can be observed on concur- 
rent transbronchial biopsies (Fig. 22.4b) [55]. Second, antibody-mediated rejection (AMR), which is a rejection of the allograft by the production of antibodies directed to donor HLA molecules [56]. These antibodies may be formed prior to transplantation or de novo. Findings on transbronchial biopsies are mostly non-specific: capillary inflammation and acute lung injury, with or without diffuse alveolar damage (DAD) and endothelialitis, sometimes with evidence of endothelial capillary complement $4 d$ staining. In addition to clinical findings and transbronchial biopsies, diagnosis of AMR can be suspected when donor-specific antibodies (DSA) are found in the blood [51, 57]. Also, there is a form of AMR known as hyperacute rejection, which occurs minutes to hours after transplantation and is mediated by preformed antibodies directed toward donor HLA and ABO molecules [58].

Another cause of ALAD is azithromycin responsive allograft dysfunction (ARAD), which was previously also referred to as neutrophilic reversible allograft dysfunction (NRAD) or azithromycin responsive BOS [32]. It is characterized by active inflammatory lesions, and transbronchial biopsy is characterized by a prominent peribronchiolar infiltrate of mononuclear cells (macrophages and lymphocytes), while BAL often presents excess neutrophilia. This phenotype is important to recognize as it is treatable with azithromycin: after 3-6 months of azithromycin therapy, the forced expiratory volume in 1 second $\left(\mathrm{FEV}_{1}\right)$ decline may be reversible (defined as an $\mathrm{FEV}_{1}$ and/or FVC increase to $>90 \%$ of the best posttransplant values). HRCT typically shows air trapping, tree-in-bud opacities and peribronchiolar infiltrates, of which the last two features may improve after azithromycin therapy [32, 59, 60]. Apart from treating ARAD, azithromycin may also prevent it [61]. On the other hand, some patients do not respond to azithromycin therapy, with persistent shortness of breath and BAL neutrophilia. This azithromycin resistant neutrophilia compromises survival and is a risk factor for later CLAD [62].

Other causes of ALAD can be capillary leak syndrome, anastomotic problems (e.g., dehiscence of bronchial anastomoses) and pulmonary embolism, among others. Infection and allograft rejection remain, however, the leading cause of rehospitalization after lung transplant (Fig. 22.5).
Fig. 22.5 Rehospitalisation post lung transplant. This figure shows the hospitalizations reported on the 1-year, 3-year, and 5-year follow-up. All follow-ups between January 2009 and June 2017 were included. (Based on data from the International Society of Heart and Lung Transplantation)

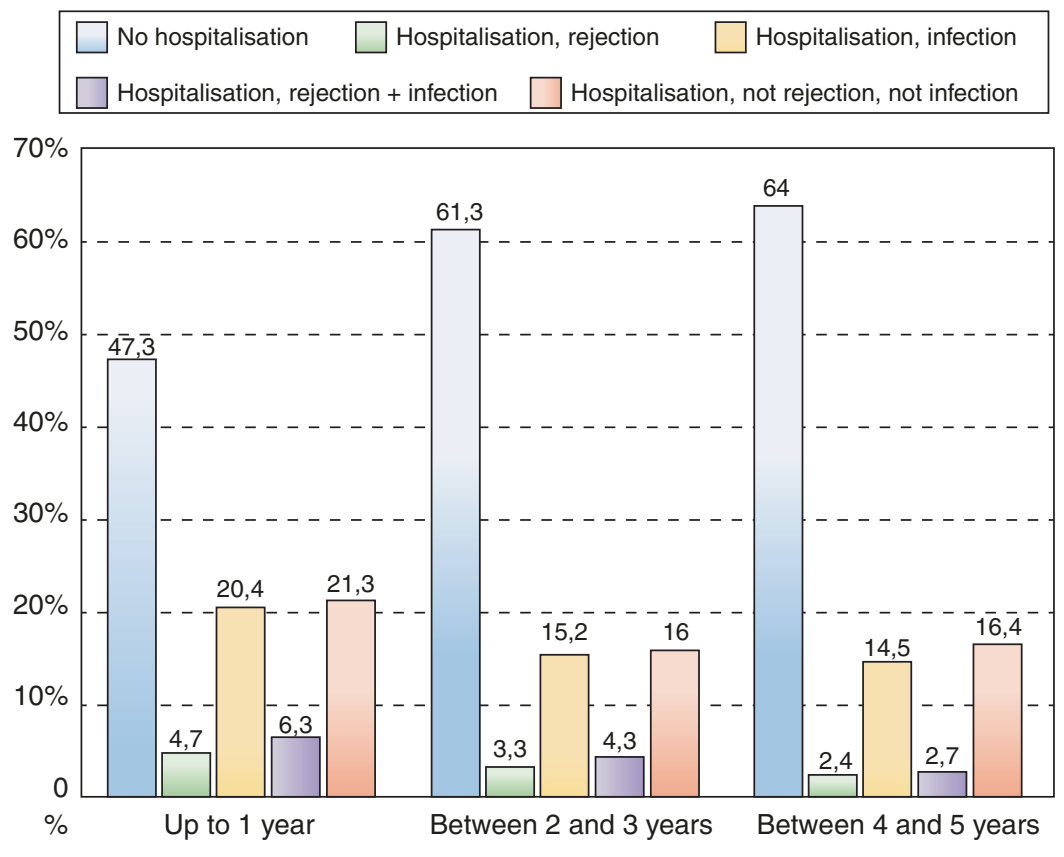




\section{Chronic Lung Allograft Dysfunction}

This part will mainly focus on the causes of longterm deterioration of pulmonary function, but one has to keep in mind that due to the chronic use of immunosuppressive drugs, lung transplant patients have an increased risk to develop malignant conditions (e.g., lymphoproliferative disorder), infections, or other complications (e.g., increased cardiovascular risk, kidney failure, among others).

CLAD is a term that encompasses chronic lung dysfunction after transplantation that is not explained by other conditions. CLAD is defined as a persistent (at least 3 weeks), often progressive, decline in pulmonary function $\left(\mathrm{FEV}_{1}\right.$ with/ without FVC) $\geq 20 \%$ from baseline (baseline defined as the average of the two best posttransplant values for $\mathrm{FEV}_{1}$ and $\mathrm{FVC}$ obtained at least 3 weeks apart) [32, 63]. Potential CLAD is defined as a persistent (at least 3 weeks), otherwise unexplained decline in pulmonary function $\geq 10 \%$ from baseline. Potential CLAD should always trigger an in-depth investigation of possible causes of pulmonary function decline, including blood sampling (HLA-antibodies, infection parameters), full pulmonary function testing (measurement of total lung capacity (TLC) and residual volume (RV), in addition to spirometry), transbronchial biopsy specimen analysis, BAL with total and differential cell count, and chest HRCT with inspiratory and expiratory imaging. If no cause is found, trial therapy with azithromycin should be started to differentiate between CLAD and ARAD (see Fig. 22.6) [32, 63]. Definite CLAD is a term used when all other causes are treated or excluded, azithromycin trial therapy was not or only partially successful, and lung allograft dysfunction continues for at least 3 months [63]. CLAD is a common long-term complication, its prevalence increasing over post lung transplantation time (Fig. 22.7) [11].

There are several different terms in the literature: CLAD, BOS, chronic rejection, and obliterative bronchiolitis (OB) are used interchangeably, which needs clarification. OB is a histopathologic term that was the main finding initially described in autopsies from patients who were believed to have died of chronic rejection. Because of the clinical need for a clinical definition instead of a histological one, the term bronchiolitis obliterans syndrome (BOS) was proposed, which was defined by spirometry by Cooper et al. [64]. A few years ago, more and more patients with an $\mathrm{FEV}_{1}$-decline associated with a restrictive pulmonary defect were reported, which led to the introduction of restrictive allograft syndrome (RAS) [65]. CLAD should not be used as a synonym for BOS or RAS, but includes all cases of BOS and RAS and mixed phenotypes of RAS and BOS. CLAD encompasses multiple causes of chronic lung dysfunction and is therefore also no synonym for chronic rejection.

Thus, CLAD is an umbrella term, not a final diagnosis. Furthermore, before the use of the term CLAD, other causes of a decreased pulmonary function must be excluded, and reversibility after azithromycin must be assessed. Therefore, potential CLAD patients should be thoroughly investigated to find a specific cause of persistent decreased pulmonary function. There are several non-CLAD causes of pulmonary function decline (previously referred to as nonBOS, non-RAS CLAD) [32]. These can be either allograft-related (persistent infection, persistent acute rejection, anastomotic strictures, disease recurrence) or non-allograft-related (pleural disorders, diaphragmatic dysfunction, obesity, ascites, and chronic kidney failure, among others), or a combination of both. Despite the possibility of specific treatment, patients with identifiable causes of chronic pulmonary function decline show equally decreased survival compared to BOS or RAS [32, 66].

When no specific cause is found, and the $\mathrm{FEV}_{1}$ decline is not only persistent but also purely obstructive $\left(\mathrm{FEV}_{1} / \mathrm{FVC}<0.70\right.$, with no drop in TLC) the term BOS should be used to describe this clinical phenotype (Fig. 22.8a). BOS accounts for approximately $70 \%$ of CLAD patients [65, 67]. Histopathological reports from transbronchial biopsies and autopsy specimens show fibrotic lesions of the bronchioles, known as OB lesions, with sur- 


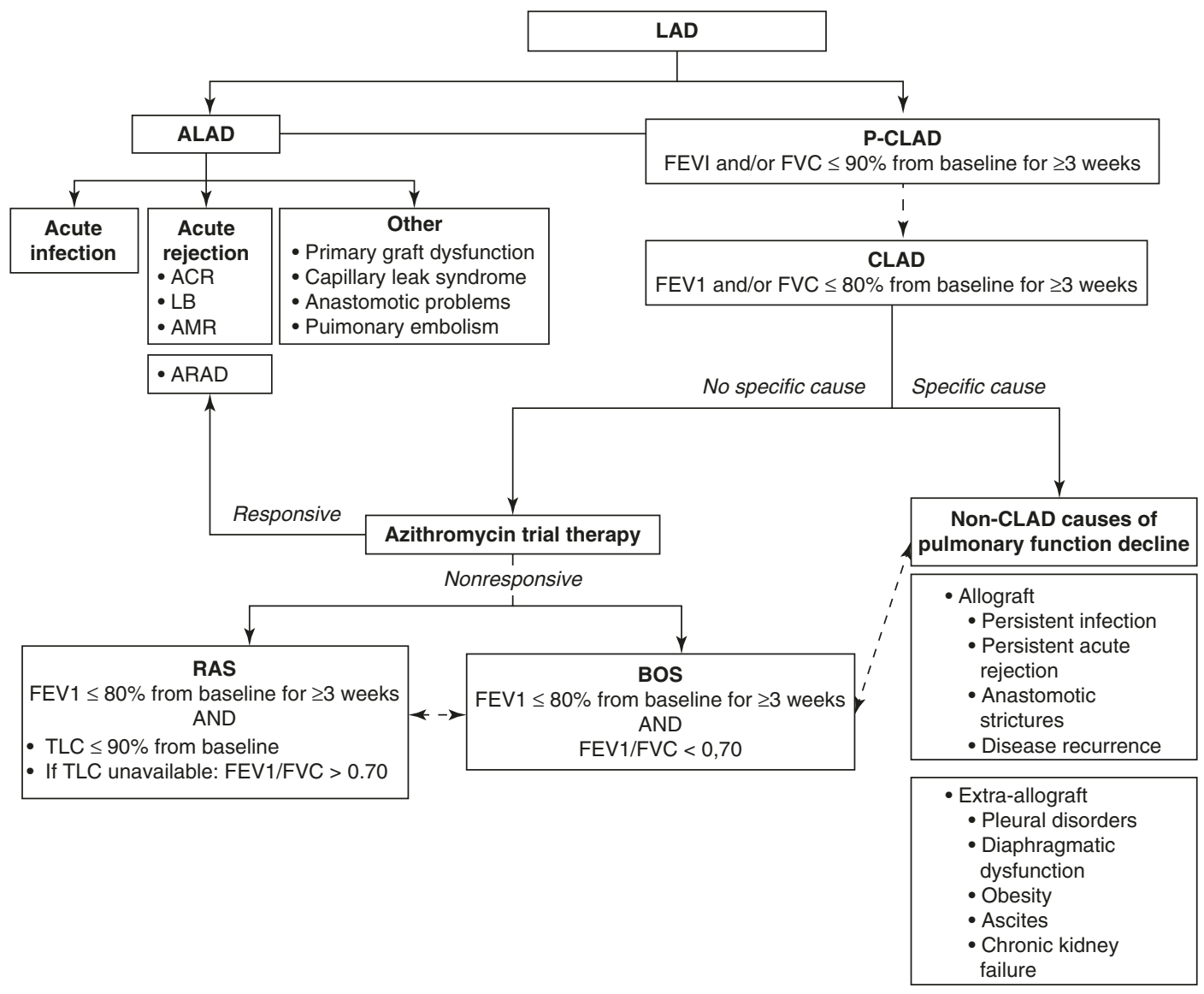

Fig. 22.6 Diagnosis of chronic lung allograft dysfunction [32]. In the case of suspected CLAD, all other causes of a decrease in FEV1 should be excluded. If no cause is found, a trial therapy with azithromycin should be started. If a patient is responsive (defined as an improvement in FEV1 with $\geq 10 \%$ after $3-6$ months azithromycin), this phenotype is referred to as ARAD. If a patient is nonresponsive, further investigations should differentiate between BOS and RAS. LAD lung allograft dysfunction,

rounding normal parenchyma, as well as collapse lesions [68, 69]. HRCT changes, like air trapping with or without bronchiectasis, can be observed (Fig. 22.8b). There should be no persistent infiltrates on HRCT. In contrast to ARAD, BOS is not fully responsive to azithromycin therapy [32].

A persistent $\mathrm{FEV}_{1}$ decline with no specific cause, accompanied by a persistent decline in TLC ( $>10 \%$ compared to baseline) is defined as restrictive allograft syndrome (RAS) (Fig. 22.8c), also referred to as restrictive CLAD (r-CLAD).
$\mathrm{FEV}_{1}$ forced expiratory volume in 1 second, FVC forced vital capacity, TLC total lung capacity, ALAD acute lung allograft dysfunction, CLAD chronic lung allograft dysfunction, P-CLAD potential chronic lung allograft dysfunction, ACR acute cellular rejection, LB lymphocytic bronchiolitis, AMR antibody-mediated rejection, ARAD azithromycin responsive allograft dysfunction, RAS restrictive allograft syndrome, BOS bronchiolitis obliterans syndrome

RAS accounts for approximately $30 \%$ of CLAD $[65,67]$. When TLC is not available, $\mathrm{FEV}_{1} / \mathrm{FVC}$ can be used as a surrogate marker $\left(\mathrm{FEV}_{1} /\right.$ FVC > 0.70). RAS has a lower survival rate compared to BOS, and the cause of this poor prognosis is unclear [32, 70]. Histopathology obtained from explanted lungs shows pleural and septal thickening and parenchymal fibrosis in the lung periphery [65]. HRCT demonstrates changes such as interstitial opacities, ground-glass opacities, upper lobe dominant fibrosis, and honeycombing (Fig. 22.8d) [32]. The RAS phenotype 
is still a very heterogeneous entity, and there are no clear-cut guidelines for diagnosis. As a result, there is some overlap with other (histological) phenotypes, such as acute fibrinous and organizing pneumonia (AFOP), pleuroparenchymal fibroelastosis (PPFE) and diffuse alveolar damage (DAD). There is still debate whether these phenotypes are pathological subtypes of RAS or represent separate clinical entities [71].

These CLAD subtypes are not permanent, and there may be some overlap: some patients initially display a typical $\mathrm{FEV}_{1}$ decline compatible with BOS, but may subsequently develop the RAS phenotype. The frequency of each subtype
Fig. 22.7 Kaplan Meier CLAD curve after lung transplantation. Lung transplantations performed from January 2004 till December 2015 in UZ Leuven, Belgium were included. CLAD chronic lung allograft dysfunction, LTx lung transplantation

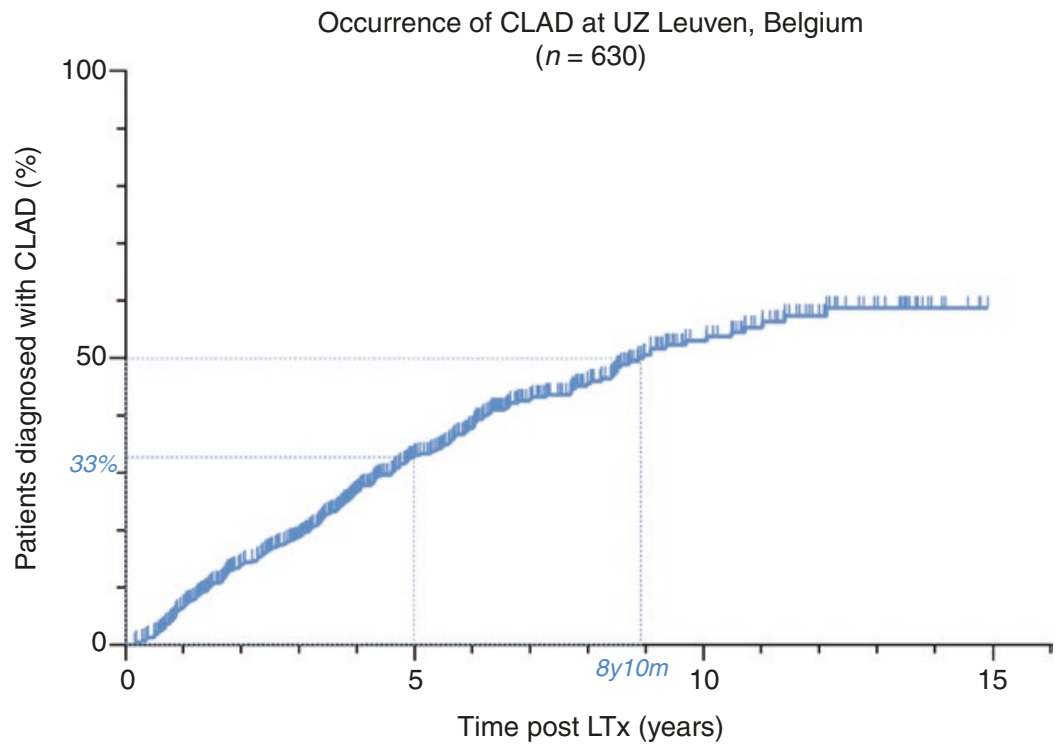

a
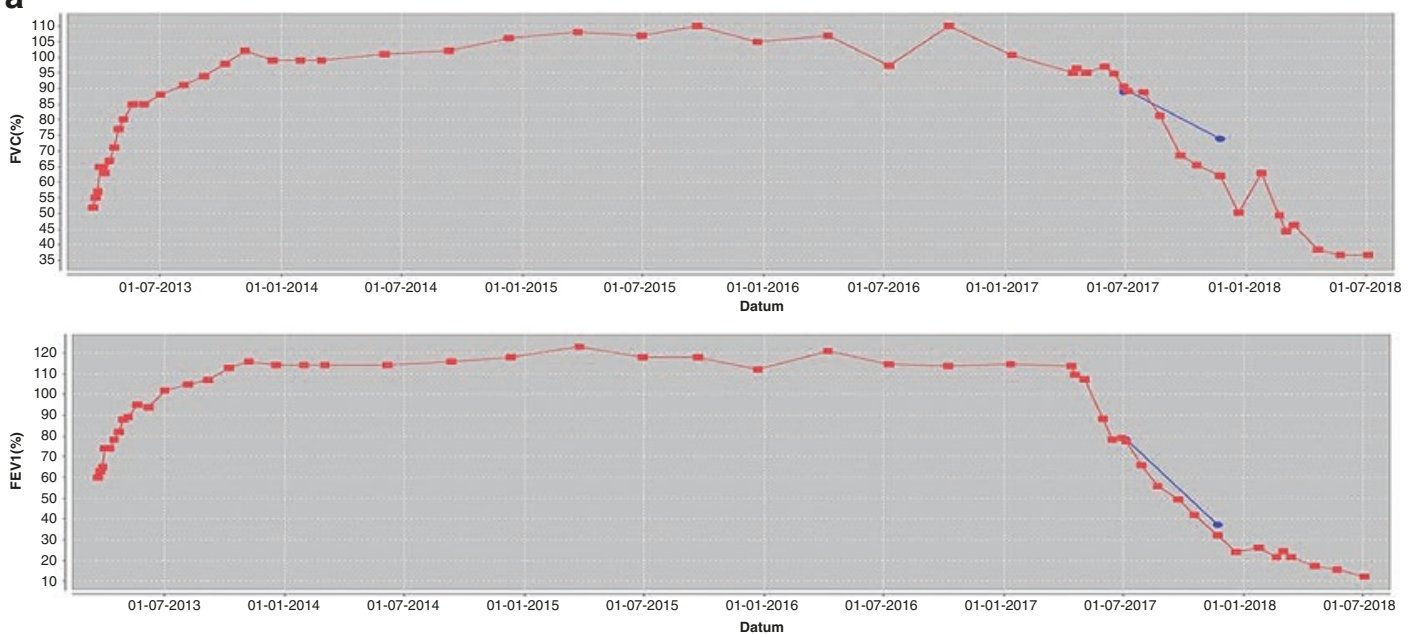

Fig. 22.8 Clinical features of RAS and BOS. (a) Pulmonary function of a patient diagnosed with BOS. The upper graph shows a decline in FVC, the lower graph a decline in FEV1. (b) HRCT of a patient diagnosed with BOS (c) Pulmonary function of a patient diagnosed with RAS. The upper graph shows a decline in FVC, the mid- dle graph a decline in FEV1 and the lower graph a decline in TLC. (d) HRCT of a patient diagnosed with RAS. BOS bronchiolitis obliterans syndrome, FVC forced vital capacity, FEV1 forced expiratory volume in 1 second, HRCT high resolution computed tomography, RAS restrictive allograft syndrome, TLC total lung capacity 

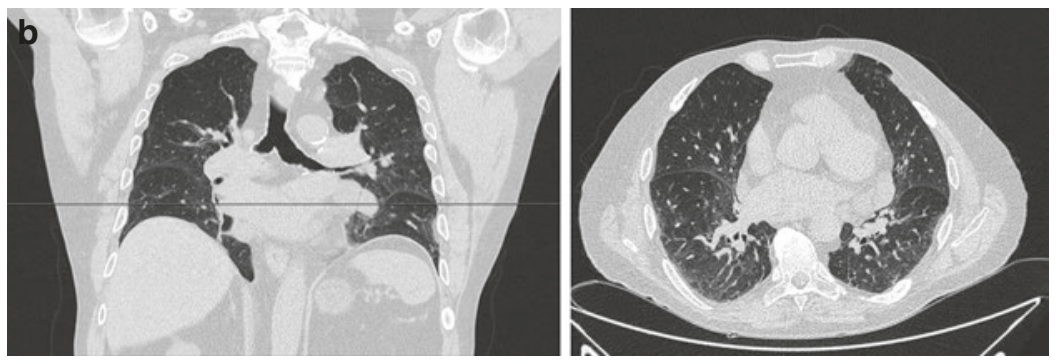

C
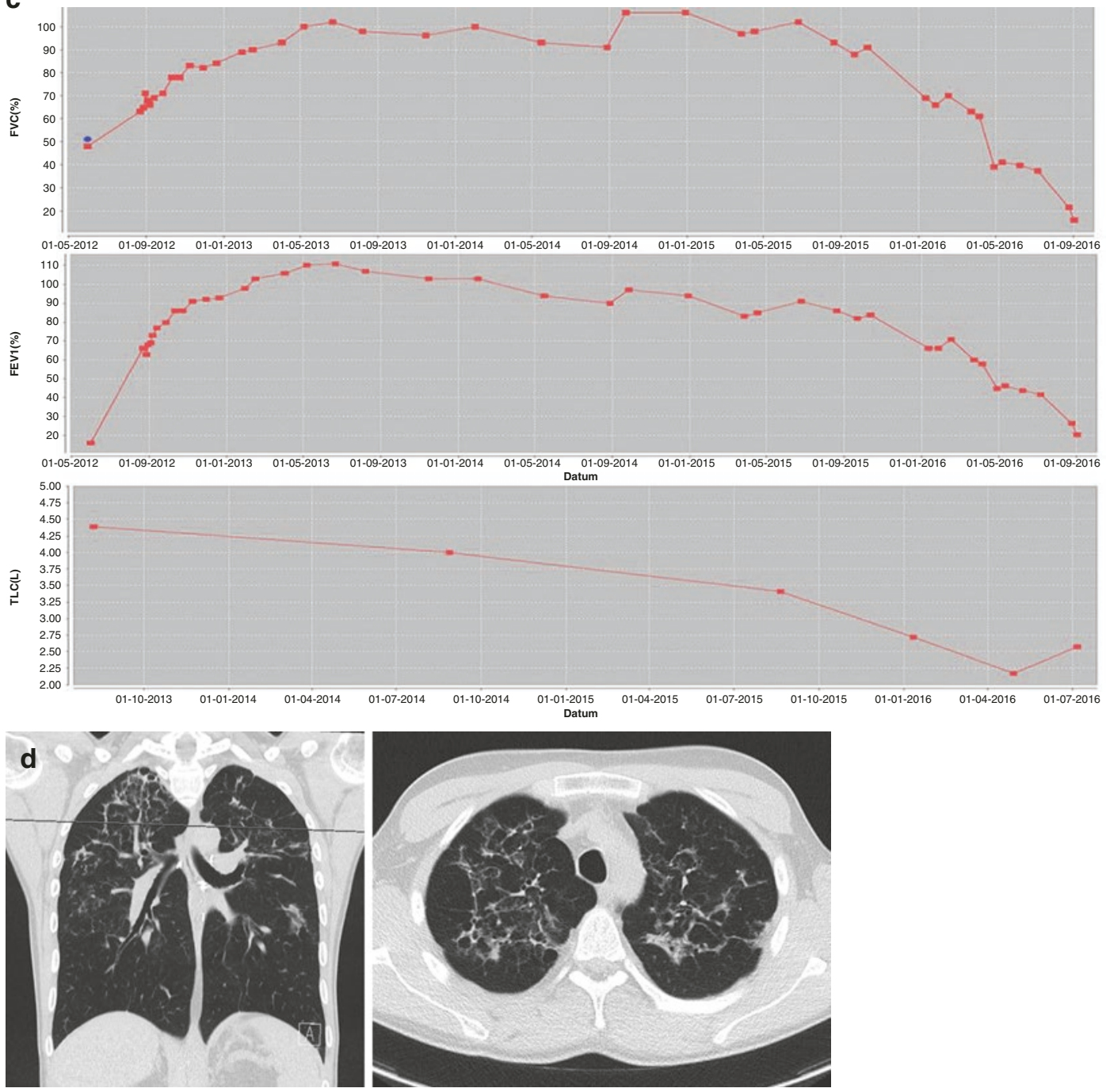

Fig. 22.8 (continued) 
can be found in Fig. 22.9. Development of persistent parenchymal infiltrates on HRCT seems predictive of the conversion from BOS to RAS, even when initially the pulmonary function status is not consistent with a restrictive pattern. Likewise, some patients may first develop RAS, but end up with the classical BOS phenotype after the resolution of their infiltrates. Table 22.5 shows an overview of the key features of the phenotypes of CLAD [32]. Many factors may contribute to the development of CLAD. Reported risk factors for RAS and BOS seem fairly similar and are summed up in Table 22.6 [72-74].

As mentioned before, every lung transplant patient receives life-long treatment with immunosuppressive drugs in order to avoid graft rejection [31]. Treatment of CLAD by increasing or shifting immunosuppression (cyclosporin to tacrolimus, azathioprine to mycophenolate) and/ or steroids results at best in a temporary slowing the decline of pulmonary function $[75,76]$. The addition of azithromycin may improve lung function in a subset of CLAD patients (mainly the BOS phenotype), even if they were not fully responsive to azithromycin therapy before, due to various anti-inflammatory and immunomodulatory properties, mainly targeting neutrophils [7779]. There is also evidence that prophylactic azithromycin initiated at discharge post lung transplantation can reduce CLAD prevalence and improve CLAD-free survival and pulmonary function [79, 80]. Also, several new therapies have been introduced, which may attenuate CLAD progression: total lymphoid irradiation (TLI), extracorporeal photophoresis (ECP), fundoplication, mTOR inhibitors, montelukast (a leukotriene receptor antagonist), and pirfenidone [81-88]. Whether it may be beneficial to lower immunosuppressive therapy, a therapeutic approach already practiced in other solid organ transplantation patients, e.g., kidney transplantation patients, remains elusive [89-92].

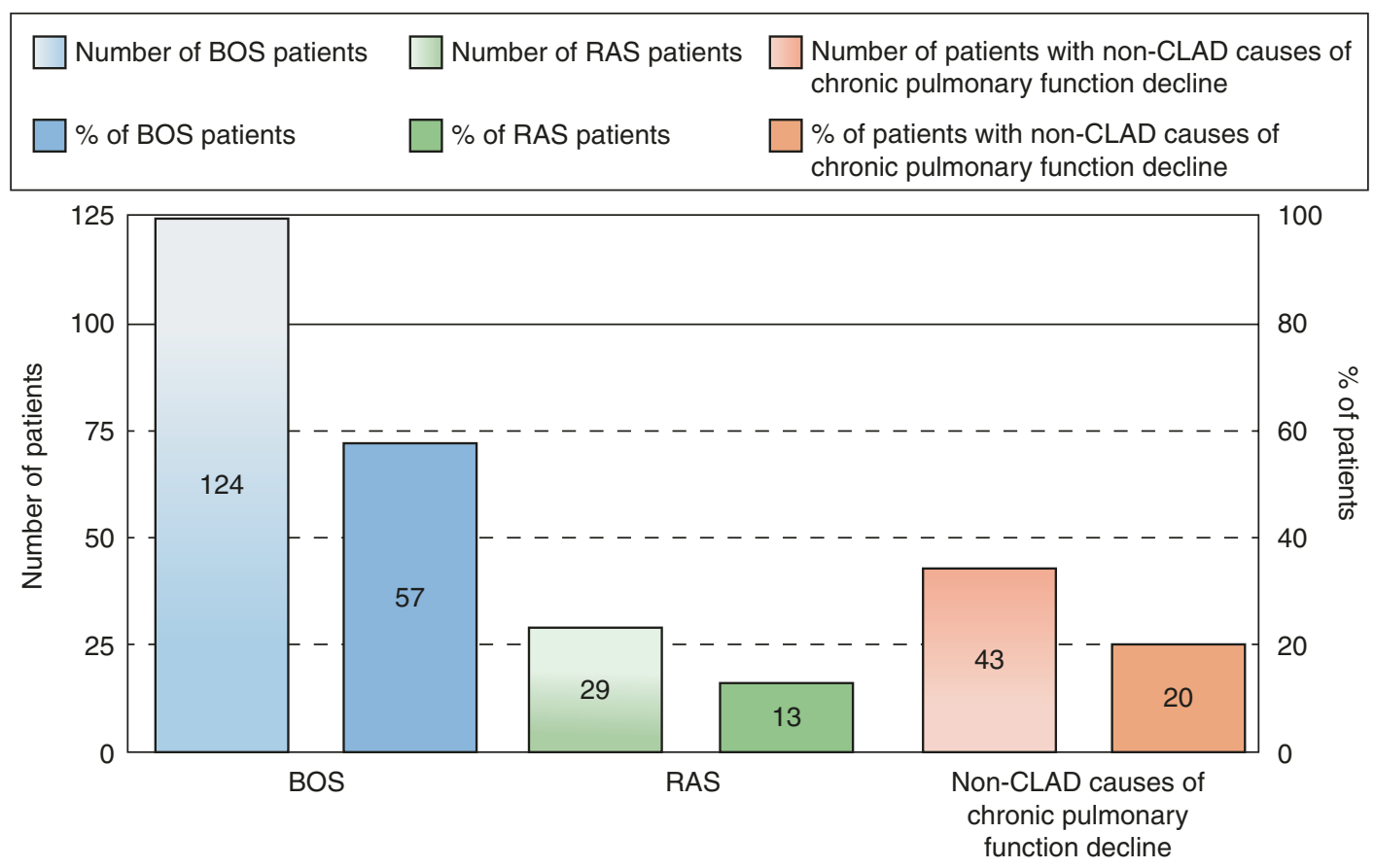

Fig. 22.9 Prevalence of causes of chronic pulmonary function decline [66]. CLAD chronic lung allograft dysfunction, RAS restrictive allograft syndrome, BOS bronchiolitis obliterans syndrome 
Table 22.5 Key features of the main phenotypes of chronic lung allograft dysfunction [32]

\begin{tabular}{l|l|l}
\hline Entity & Classic BOS & RAS \\
\hline \multirow{2}{*}{$\begin{array}{l}\text { Pulmonary } \\
\text { function }\end{array}$} & Obstructive $\left(\mathrm{FEV}_{1} / \mathrm{FVC}<0.70\right)$ & $\begin{array}{l}\text { Restrictive }(\mathrm{TLC} \leq 90 \% \text { of stable baseline value) } \\
\text { and/or FEV } / \mathrm{FVC}>0.70\end{array}$ \\
\hline \multirow{2}{*}{$\begin{array}{l}\text { HRCT thoracic } \\
\text { imaging }\end{array}$} & $\mathrm{FEV}_{1} \leq 80 \%$ of stable baseline value & $\mathrm{FEV}_{1}$ decline $\leq 80 \%$ of stable baseline value \\
\cline { 2 - 3 } & No/minimal infiltrates & Infiltrates usually present \\
\cline { 2 - 3 } & With/without bronchiectasis & With/without air trapping \\
\hline Histopathology & $\begin{array}{l}\text { OB (difficult to diagnose by } \\
\text { transbronchial biopsy specimen) }\end{array}$ & With/without bronchiectasis \\
\hline \multirow{2}{*}{ Clinical course } & Typically progressive but may stabilize & Tends to be relentlessly progressive \\
\cline { 2 - 3 } & May evolve to RAS & May start as or coincide with BOS \\
\cline { 2 - 3 } & $\begin{array}{l}\text { Recipients may have coexistent chronic } \\
\text { bacterial infection }\end{array}$ & $\begin{array}{l}\text { Correlates with the presence of early diffuse } \\
\text { alveolar damage posttransplant }\end{array}$ \\
\hline
\end{tabular}

$B O S$ bronchiolitis obliterans syndrome, $R A S$ restrictive allograft syndrome, $F E V_{1}$ forced expiratory volume in 1 second, $F V C$ forced vital capacity, $T L C$ total lung capacity, $O B$ obliterative bronchiolitis

Table 22.6 Risk factors for RAS and BOS [72-74]

\begin{tabular}{l}
\hline Allo-immune dependent risk factors \\
\hline Acute allograft rejection \\
\hline Acute cellular rejection -A-grade \\
\hline Acute antibody mediated rejection \\
\hline Lymphocytic bronchiolitis \\
\hline Azithromycin responsive allograft dysfunction \\
\hline HLA mismatch \\
\hline Allo-immune independent risk factors \\
\hline Primary graft dysfunction \\
\hline Infection and colonization \\
\hline Viral \\
\hline Bacterial \\
\hline Fungal
\end{tabular}

Persistent neutrophil influx and sequestration (elevated BAL neutrophilia)

Airway eosinophilia (elevated BAL eosinophilia)

Recipient age

Donor age

Autoimmunity (e.g., collagen V sensitization)

Ischemic time

Air pollution

Genetic factors

$B O S$ bronchiolitis obliterans syndrome, $R A S$ restrictive allograft syndrome, $B A L$ bronchoalveolar lavage

\section{Conclusion}

Lung transplantation is a life-saving intervention in patients with advanced lung disease. Although the technical aspects of the procedure have evolved significantly since the earlier days of the technique, the main challenge to precision and long-term survival after lung transplantation is the recognition and management of CLAD. Prevention of CLAD is an important approach as therapeutic strategies have been largely unsuccessful. CLAD, however, covers different phenotypes, with different pathophysiological mechanisms and different clinical characteristics. Specifically tailored therapeutic regimes have yet to be developed. Nevertheless, lung transplantation is moving forward: with more and more experience in all centers, survival is improving (Fig. 22.10) and will hopefully soon reach the level of other solid organ transplantations. 
Fig. 22.10 Kaplan Meier Survival curve after lung transplantation. Lung transplantations performed in UZ Leuven, Belgium from July 1991 till December 2018 in the KU Leuven Lung Transplant Unit were included

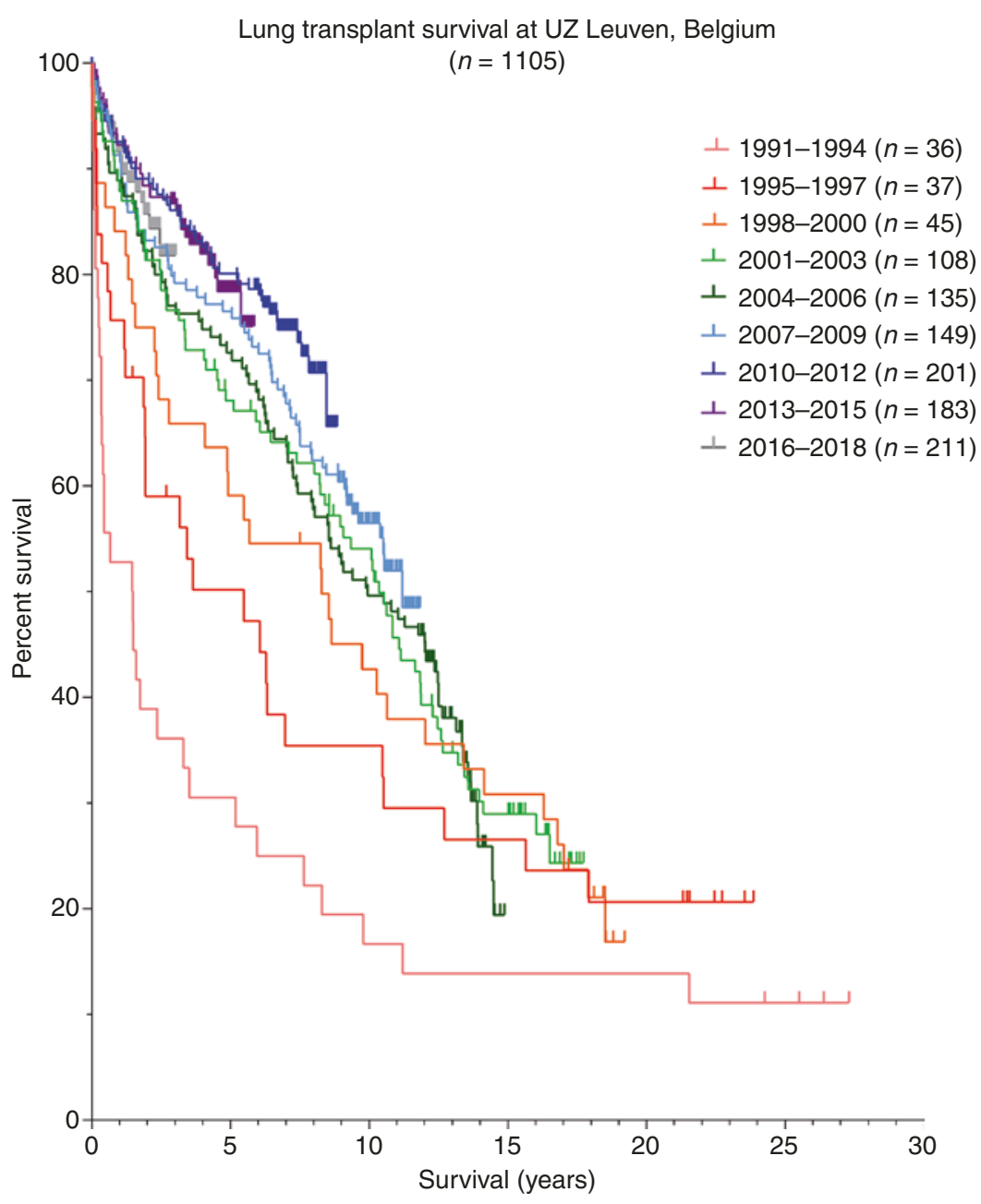

\section{References}

1. Benfield JR, Wain JC. The history of lung transplantation. Chest Surg Clin N Am. 2000;10:189-99, xi.

2. Steen S, Sjöberg T, Pierre L, et al. Transplantation of lungs from a non-heart-beating donor. Lancet. 2001;357:825-9.

3. Burke CM, Theodore J, Baldwin JC, et al. Twentyeight cases of human heart-lung transplantation. Lancet. 1986;1:517-9.

4. Theodore J, Jamieson SW, Burke CM, et al. Physiologic aspects of human heart-lung transplantation. Pulmonary function status of the posttransplanted lung. Chest. 1984;86:349-57.

5. Yusen RD, Edwards LB, Kucheryavaya AY, et al. The registry of the International Society for Heart and Lung Transplantation: thirty-first adult lung and heart-lung transplant report--2014; focus theme: retransplantation. J Heart Lung Transplant. 2014;33:1009-24.
6. Frost AE. Donor criteria and evaluation. Clin Chest Med. 1997;18:231-7.

7. Wille KM, Harrington KF, deAndrade JA, et al. Disparities in lung transplantation before and after introduction of the lung allocation score. J Heart Lung Transplant. 2013;32:684-92.

8. Van Raemdonck D, Neyrinck A, Verleden GM, et al. Lung donor selection and management. Proc Am Thorac Soc. 2009;6:28-38.

9. Ceulemans LJ, Monbaliu D, Verslype C, et al. Combined liver and lung transplantation with extended normothermic lung preservation in a patient with endstage emphysema complicated by drug-induced acute liver failure. Am J Transplant. 2014;14:2412-6.

10. Cypel M, Yeung JC, Hirayama S, et al. Technique for prolonged normothermic ex vivo lung perfusion. J Heart Lung Transplant. 2008;27:1319-25.

11. Chambers DC, Yusen RD, Cherikh WS, et al. The registry of the International Society for Heart and 
Lung Transplantation: thirty-fourth adult lung and heart-lung transplantation report-2017; focus theme: allograft ischemic time. J Heart Lung Transplant. 2017;36:1047-59.

12. Hart A, Smith JM, Skeans MA, et al. OPTN/SRTR 2016 annual data report: kidney. Am J Transplant. 2018;18(Suppl 1):18-113.

13. Weill D, Benden C, Corris PA, et al. A consensus document for the selection of lung transplant candidates: 2014--an update from the Pulmonary Transplantation Council of the International Society for Heart and Lung Transplantation. J Heart Lung Transplant. 2015;34:1-15.

14. Nathan SD. Lung transplantation: diseasespecific considerations for referral. Chest. 2005;127:1006-16.

15. Kotloff RM, Thabut G. Lung transplantation. Am J Respir Crit Care Med. 2011;184:159-71.

16. Somers J, Ruttens D, Verleden SE, et al. A decade of extended-criteria lung donors in a single center: was it justified? Transpl Int. 2015;28:170-9.

17. Smits JM, van der Bij W, Van Raemdonck D, et al. Defining an extended criteria donor lung: an empirical approach based on the Eurotransplant experience. Transpl Int. 2011;24:393-400.

18. Schiavon M, Falcoz P-E, Santelmo N, et al. Does the use of extended criteria donors influence early and long-term results of lung transplantation? Interact Cardiovasc Thorac Surg. 2012;14:183-7.

19. Bittle GJ, Sanchez PG, Kon ZN, et al. The use of lung donors older than 55 years: a review of the United Network of Organ sharing database. J Heart Lung Transplant. 2013;32:760-8.

20. Carrier M, Lizé J-F. Québec-Transplant Programs. Impact of expanded-criteria donors on patient survival after heart, lung, liver and combined organ transplantation. Transplant Proc. 2012;44:2231-4.

21. Ingemansson R, Eyjolfsson A, Mared L, et al. Clinical transplantation of initially rejected donor lungs after reconditioning ex vivo. Ann Thorac Surg. 2009;87:255-60.

22. Fildes JE, Archer LD, Blaikley J, et al. Clinical outcome of patients transplanted with marginal donor lungs via ex vivo lung perfusion compared to standard lung transplantation. Transplantation. 2015;99:1078-83.

23. Cypel M, Keshavjee S. Extending the donor pool: rehabilitation of poor organs. Thorac Surg Clin. 2015;25:27-33.

24. Cypel M, Rubacha M, Yeung J, et al. Normothermic ex vivo perfusion prevents lung injury compared to extended cold preservation for transplantation. Am J Transplant. 2009;9:2262-9.

25. Cypel M, Yeung JC, Liu M, et al. Normothermic ex vivo lung perfusion in clinical lung transplantation. N Engl J Med. 2011;364:1431-40.

26. De Vleeschauwer SI, Wauters S, Dupont LJ, et al. Medium-term outcome after lung transplantation is comparable between brain-dead and cardiac-dead donors. J Heart Lung Transplant. 2011;30:975-81.
27. Bartosik W, Egan JJ, Wood AE. The Novalung interventional lung assist as bridge to lung transplantation for self-ventilating patients - initial experience. Interact Cardiovasc Thorac Surg. 2011;13:198-200.

28. Hoetzenecker K, Donahoe L, Yeung JC, et al. Extracorporeal life support as a bridge to lung transplantation-experience of a high-volume transplant center. J Thorac Cardiovasc Surg. 2018;155:1316-1328.e1.

29. Vasanthan V, Garg M, Maruyama M, et al. Extended bridge to heart and lung transplantation using pumpless extracorporeal lung assist. Can J Cardiol. 2017;33:950.e11-3.

30. Mayes J, Niranjan G, Dark J, et al. Bridging to lung transplantation for severe pulmonary hypertension using dual central Novalung lung assist devices. Interact Cardiovasc Thorac Surg. 2016;22:677-8.

31. Scheffert JL, Raza K. Immunosuppression in lung transplantation. J Thorac Dis. 2014;6:1039-53.

32. Verleden GM, Raghu G, Meyer KC, et al. A new classification system for chronic lung allograft dysfunction. J Heart Lung Transplant. 2014;33:127-33.

33. Sato M, Hwang DM, Ohmori-Matsuda K, et al. Revisiting the pathologic finding of diffuse alveolar damage after lung transplantation. J Heart Lung Transplant. 2012;31:354-63.

34. Castro CY. ARDS and diffuse alveolar damage: a pathologist's perspective. Semin Thorac Cardiovasc Surg. 2006;18:13-9.

35. Snell GI, Yusen RD, Weill D, et al. Report of the ISHLT Working Group on Primary Lung Graft Dysfunction, part I: definition and grading-A 2016 Consensus Group statement of the International Society for Heart and Lung Transplantation. J Heart Lung Transplant. 2017;36:1097-103.

36. Christie J, Keshavjee S, Orens J, et al. Potential refinements of the International Society for Heart and Lung Transplantation primary graft dysfunction grading system. J Heart Lung Transplant. 2008;27:138.

37. Christie JD, Van Raemdonck D, de Perrot M, et al. Report of the ISHLT Working Group on Primary Lung Graft Dysfunction part I: introduction and methods. J Heart Lung Transplant. 2005;24:1451-3.

38. Suzuki Y, Cantu E, Christie JD. Primary graft dysfunction. Semin Respir Crit Care Med. 2013;34:305-19.

39. Shah RJ, Diamond JM, Cantu E, et al. Objective estimates improve risk stratification for primary graft dysfunction after lung transplantation. Am J Transplant. 2015; 15:2188-96.

40. Diamond JM, Lee JC, Kawut SM, et al. Clinical risk factors for primary graft dysfunction after lung transplantation. Am J Respir Crit Care Med. 2013;187:527-34.

41. Christie JD, Kotloff RM, Ahya VN, et al. The effect of primary graft dysfunction on survival after lung transplantation. Am J Respir Crit Care Med. 2005;171:1312-6.

42. Lee JC, Christie JD. Primary graft dysfunction. Clin Chest Med. 2011;32:279-93. 
43. Whitson BA, Prekker ME, Herrington CS, et al. Primary graft dysfunction and long-term pulmonary function after lung transplantation. J Heart Lung Transplant. 2007;26:1004-11.

44. Daud SA, Yusen RD, Meyers BF, et al. Impact of immediate primary lung allograft dysfunction on bronchiolitis obliterans syndrome. Am J Respir Crit Care Med. 2007;175:507-13.

45. Fiser SM, Tribble CG, Long SM, et al. Ischemiareperfusion injury after lung transplantation increases risk of late bronchiolitis obliterans syndrome. Ann Thorac Surg. 2002;73:1041-7; discussion 1047-8.

46. Lee JC, Christie JD. Primary graft dysfunction. Proc Am Thorac Soc. 2009;6:39-46.

47. Bermudez CA, Adusumilli PS, McCurry KR, et al. Extracorporeal membrane oxygenation for primary graft dysfunction after lung transplantation: long-term survival. Ann Thorac Surg. 2009;87:854-60.

48. Vlasselaers D, Verleden GM, Meyns B, et al. Femoral venoarterial extracorporeal membrane oxygenation for severe reimplantation response after lung transplantation. Chest. 2000;118:559-61.

49. Novick RJ, Stitt LW, Al-Kattan K, et al. Pulmonary retransplantation: predictors of graft function and survival in 230 patients. Pulmonary retransplant registry. Ann Thorac Surg. 1998;65:227-34.

50. Nosotti M, Tarsia P, Morlacchi LC. Infections after lung transplantation. J Thorac Dis. 2018;10:3849-68.

51. Roden AC, Aisner DL, Allen TC, et al. Diagnosis of acute cellular rejection and antibody-mediated rejection on lung transplant biopsies: a perspective from members of the pulmonary pathology society. Arch Pathol Lab Med. 2017;141:437-44.

52. Fishman JA. Infection in solid-organ transplant recipients. N Engl J Med. 2007;357:2601-14.

53. Yusen RD, Edwards LB, Kucheryavaya AY, et al. The registry of the International Society for Heart and Lung Transplantation: thirty-second official adult lung and heart-lung transplantation report--2015; focus theme: early graft failure. J Heart Lung Transplant. 2015;34:1264-77.

54. De Vito Dabbs A, Hoffman LA, Iacono AT, et al. Are symptom reports useful for differentiating between acute rejection and pulmonary infection after lung transplantation? Heart Lung. 2004;33:372-80.

55. Stewart S, Fishbein MC, Snell GI, et al. Revision of the 1996 working formulation for the standardization of nomenclature in the diagnosis of lung rejection. J Heart Lung Transplant. 2007;26:1229-42.

56. Loupy A, Lefaucheur C. Antibody-mediated rejection of solid-organ allografts. $\mathrm{N}$ Engl $\mathrm{J}$ Med. 2018;379:1150-60.

57. Levine DJ, Glanville AR, Aboyoun C, et al. Antibody-mediated rejection of the lung: a consensus report of the International Society for Heart and Lung Transplantation. J Heart Lung Transplant. 2016;35:397-406.

58. Benzimra M, Calligaro GL, Glanville AR. Acute rejection. J Thorac Dis. 2017;9:5440-57.
59. Vanaudenaerde BM, Meyts I, Vos R, et al. A dichotomy in bronchiolitis obliterans syndrome after lung transplantation revealed by azithromycin therapy. Eur Respir J. 2008;32:832-43.

60. Verleden GM, Vos R, De Vleeschauwer SI, et al. Obliterative bronchiolitis following lung transplantation: from old to new concepts? Transpl Int. 2009;22:771-9.

61. Vos R, Vanaudenaerde BM, Ottevaere A, et al. Longterm azithromycin therapy for bronchiolitis obliterans syndrome: divide and conquer? J Heart Lung Transplant. 2010;29:1358-68.

62. Vandermeulen E, Verleden SE, Ruttens D, et al. BAL neutrophilia in azithromycin-treated lung transplant recipients: clinical significance. Transpl Immunol. 2015;33:37-44.

63. Verleden GM, Glanville AR, Lease ED, et al. Chronic lung allograft dysfunction: definition, diagnostic criteria and approaches to treatment. A consensus report from the pulmonary council of the ISHLT. J Heart Lung Transplant. 2019;38(5):493-503.

64. Cooper JD, Billingham M, Egan T, et al. A working formulation for the standardization of nomenclature and for clinical staging of chronic dysfunction in lung allografts. International Society for Heart and Lung Transplantation. J Heart Lung Transplant. 1993;12:713-6.

65. Sato M, Waddell TK, Wagnetz U, et al. Restrictive allograft syndrome (RAS): a novel form of chronic lung allograft dysfunction. J Heart Lung Transplant. 2011;30:735-42.

66. Van Herck A, Verleden SE, Sacreas A, et al. Validation of a post-transplant chronic lung allograft dysfunction classification system. J Heart Lung Transplant. 2019;38(2):166-73. https://doi.org/10.1016/j. healun.2018.09.020.

67. Verleden SE, Vandermeulen E, Ruttens D, et al. Neutrophilic reversible allograft dysfunction (NRAD) and restrictive allograft syndrome (RAS). Semin Respir Crit Care Med. 2013;34:352-60.

68. Verleden SE, Vasilescu DM, McDonough JE, et al. Linking clinical phenotypes of chronic lung allograft dysfunction to changes in lung structure. Eur Respir J. 2015;46:1430-9.

69. Verleden SE, Vasilescu DM, Willems S, et al. The site and nature of airway obstruction after lung transplantation. Am J Respir Crit Care Med. 2014;189:292-300.

70. Verleden SE, Todd JL, Sato M, et al. Impact of CLAD phenotype on survival after lung retransplantation: a multicentre study. Am J Transplant. 2015;15:2223-30.

71. von der Thüsen JH. Pleuroparenchymal fibroelastosis: its pathological characteristics. Curr Respir Med Rev. 2013;9:238-47.

72. Verleden SE, Ruttens D, Vandermeulen E, et al. Bronchiolitis obliterans syndrome and restrictive allograft syndrome: do risk factors differ? Transplantation. 2013;95:1167-72.

73. Verleden GM, Vos R, Vanaudenaerde B, et al. Current views on chronic rejection after lung transplantation. Transpl Int. 2015;28:1131-9. 
74. Meyer KC, Raghu G, Verleden GM, et al. An international ISHLT/ATS/ERS clinical practice guideline: diagnosis and management of bronchiolitis obliterans syndrome. Eur Respir J. 2014;44:1479-503.

75. Glanville AR, Aboyoun CL, Morton JM, et al. Cyclosporine C2 target levels and acute cellular rejection after lung transplantation. J Heart Lung Transplant. 2006;25:928-34.

76. Cairn J, Yek T, Banner NR, et al. Time-related changes in pulmonary function after conversion to tacrolimus in bronchiolitis obliterans syndrome. J Heart Lung Transplant. 2003;22:50-7.

77. Verleden GM, Vanaudenaerde BM, Dupont LJ, et al. Azithromycin reduces airway neutrophilia and interleukin-8 in patients with bronchiolitis obliterans syndrome. Am J Respir Crit Care Med. 2006;174:566-70.

78. Gerhardt SG, McDyer JF, Girgis RE, et al. Maintenance azithromycin therapy for bronchiolitis obliterans syndrome: results of a pilot study. Am J Respir Crit Care Med. 2003;168:121-5.

79. Vos R, Vanaudenaerde BM, Verleden SE, et al. A randomised controlled trial of azithromycin to prevent chronic rejection after lung transplantation. Eur Respir J. 2011;37:164-72.

80. Ruttens D, Verleden SE, Vandermeulen E, et al. Prophylactic azithromycin therapy after lung transplantation: post hoc analysis of a randomized controlled trial. Am J Transplant. 2016;16:254-61.

81. Fisher AJ, Rutherford RM, Bozzino J, et al. The safety and efficacy of total lymphoid irradiation in progressive bronchiolitis obliterans syndrome after lung transplantation. Am J Transplant. 2005;5:537-43.

82. Benden C, Speich R, Hofbauer GF, et al. Extracorporeal photopheresis after lung transplantation: a 10-year single-center experience. Transplantation. 2008;86:1625-7.

83. Meloni F, Cascina A, Miserere S, et al. Peripheral CD4(+)CD25(+) TREG cell counts and the response to extracorporeal photopheresis in lung transplant recipients. Transplant Proc. 2007;39:213-7.

84. Davis RD, Lau CL, Eubanks S, et al. Improved lung allograft function after fundoplication in patients with gastroesophageal reflux disease undergoing lung transplantation. J Thorac Cardiovasc Surg. 2003;125:533-42.

85. Gullestad L, Iversen M, Mortensen S-A, et al. Everolimus with reduced calcineurin inhibitor in thoracic transplant recipients with renal dysfunction: a multicenter, randomized trial. Transplantation. 2010;89:864-72.

86. Snell GI, Valentine VG, Vitulo P, et al. Everolimus versus azathioprine in maintenance lung transplant recipients: an international, randomized, double-blind clinical trial. Am J Transplant. 2006;6:169-77.

87. Verleden GM, Verleden SE, Vos R, et al. Montelukast for bronchiolitis obliterans syndrome after lung transplantation: a pilot study. Transpl Int. 2011;24:651-6.

88. Vos R, Verleden SE, Ruttens D, et al. Pirfenidone: a potential new therapy for restrictive allograft syndrome? Am J Transplant. 2013;13:3035-40.

89. Rajab A, Pelletier RP, Henry ML, et al. Excellent clinical outcomes in primary kidney transplant recipients treated with steroid-free maintenance immunosuppression. Clin Transpl. 2006;20:537-46.

90. Cantarovich D, Vistoli F, Soulillou J-P. Immunosuppression minimization in kidney transplantation. Front Biosci. 2008;13:1413-32.

91. Steiner RW. Steroid-free chronic immunosuppression in renal transplantation. Curr Opin Nephrol Hypertens. 2012;21:567-73.

92. Weaver DJ, Selewski D, Janjua H, et al. Improved cardiovascular risk factors in pediatric renal transplant recipients on steroid avoidance immunosuppression: a study of the Midwest Pediatric Nephrology Consortium. Pediatr Transplant. 2016;20:59-67. 